\title{
Mathematics as a Tool for Efficient Fishery Management and Economic Growth in Gashua, Yobe State, Nigeria
}

\author{
Anthony Anya Okeke ${ }^{1, *}$, Ahmed Dauda Abubakar ${ }^{1}$, Jerimiah Jerry Gambo ${ }^{1}$, \\ Phidelia Ramatu Waziri-Ugwu ${ }^{2}$ \\ ${ }^{1}$ Department of Mathematics, Faculty of Science, Federal University Gashua, Gashua, Nigeria \\ ${ }^{2}$ Department of Agricultural Economics \& Extension, Faculty of Agriculture, Federal University Gashua, Gashua, Nigeria
}

\section{Email address:}

anyaokeke@gmail.com (A. A. Okeke), ahmeddauda8@gmail.com (A. D. Abubakar), gambojeremiahjerry@gmail.com (J. J. Gambo), phideliawaziri@gmail.com. (P. R. Waziri-Ugwu)

${ }^{*}$ Corresponding author

\section{To cite this article:}

Anthony Anya Okeke, Ahmed Dauda Abubakar, Jerimiah Jerry Gambo, Phidelia Ramatu Waziri-Ugwu. Mathematics as a Tool for Efficient Fishery Management and Economic Growth in Gashua, Yobe State, Nigeria. Mathematical Modelling and Applications.

Vol. 5, No. 3, 2020, pp. 138-145. doi: 10.11648/j.mma.20200503.12

Received: May 4, 2020; Accepted: May 25, 2020; Published: June 16, 2020

\begin{abstract}
In this research, we propose the use of mathematical models in determining harvesting strategies for fish farming. The work considered three logistic growth models, namely constant harvesting, periodic harvesting, and proportional harvesting model. For each of the scheme, it is estimated the optimal amount of fish harvested to protect the population from extinction. The data for this work are obtained from fish owners of selected pond in Bade (Gashua). Although, fish farming has been commercialized in Bade but there is little or no literature available in studying fish harvesting strategies. The Logistic model is appropriate for population growth of fishes when overcrowding and competition for the resource are taken into consideration. The objectives of the study where to estimate the highest continuing yield from fish harvesting strategies implemented. We compare the results obtained between the three strategies and observed the best harvesting strategy for the selected fish farm is periodic (seasonal) harvesting. The periodic harvesting strategy optimizes the harvest while maintaining stable the population of fish if the harvesting is lower or equal with the bifurcation point. Our findings can assist fish farmers in Bade, Yobe State, North East Nigeria, to increase fish supply to meet its demand and positively affect the economic growth of the area.
\end{abstract}

Keywords: Biomathematics, Fishery Management, Logistic Growth Models, Harvesting, Periodic

\section{Introduction}

For quite some time, fishery business has become an enterprise cherished by the Yobe State Government, most especially in the ancient city of Bade (Gashua). It is a known fact that fish is one of the chief sources of human diet and the main source of protein and fat [1]. Lately, consumers have developed a relative interest in fish as healthy alternative meat that prevents the so-called problem of overweight and cardiovascular diseases in human health [2]. However, fisheries around the world make essential contributions to human wellbeing, providing basic food supplies, employment, livelihoods, recreational opportunities, sources of a foreign currency or recreational opportunities for hundreds of millions of people. There is an integral component of communities and societies almost wherever humans have access to water bodies: oceans, seas, lakes, and rivers [3]. According to [4], the fish available for human consumption comes either from the ocean or the sea but unfortunately, the natural supply cannot satisfy the human needs. On the other hand, the cost of fish harvesting is increasing, making aquaculture an important source for fish supply. Aquaculture production is playing an increasing role in satisfying demand for human consumption of fish and fishery products. In fact, fisheries, in general, provide many benefits to human beings and overfishing can reduce the fish stock or business of reproductive age below sustainability.

Fisheries management is the process that has evolved to ensure that fisheries operate in a manner that not only provides the immediate benefits but also does not result in excessive or irreversible damage to the exploited fish stocks or the diversity, integrity and structure of the ecosystem, so that the stocks and 
ecosystem will continue to provide the full range of benefits in the future [5]. Historically, marine fishery resources were assumed to be almost limitless, and fishing was taught to have little impact on fish biomass and marine ecosystems. However, in recent years, concern about the condition of fisheries has increased. Hence, many fisheries experts and fishermen now realize that fishing can have serious effects on marine fish stocks and the ecosystem they inhabit. In addition, the management of a renewable resource, such as fishery requires a strategy that will allow an optimum harvest rate and yet not extinct the population below a sustainable level.

A Mathematical model has been used widely to estimate the population dynamics of animals for so many years as well as the human population dynamics. In recent years, the use of mathematical models has been extended to the agriculture sector especially in cattle farming to ensure continuous and optimum supply [2]. Thus, Fisheries management policies and practices are usually based on catch effort dynamics with little consideration for the ecosystem variations.

The management has been successful in some cases but in recent decades there have also been many cases of failure. As a result, there is global concern about the state of most aquatic ecosystems and their ability to continue to provide benefits, not least the production of fish for human use.

The Food and Agricultural Organization of the United Nation [3] gave reasons for this widespread problem to, include amongst others: scientific uncertainty; an inherent conflict between short-term social and economic needs and goals and the longer-term need for sustainability; poor management practices in the past, particularly the absence of long-term rights and failing to ensure that stakeholders participate in management; insufficient capacity within the management agencies and others.

Harvesting has been an area of much interest with regards to the population as well as in community dynamics [6]. The use of mathematical models in fishery harvesting helps the aqua-culturists to estimate the fish population for a given period. In addition, the models provide effective solutions with regard to the consumer's demand [4].

According to [7], the first to formulate the theoretical treatment of population dynamics in 1798 was Thomas Malthus, Essay on the Principle of Population. Malthus had argued that, while populations grow logarithmically, the resources on which they depend remain constant or only increase arithmetically. Forty years later, in 1838, Verhulst formed the Malthus' theory (principle of population) into a mathematical model called the logistic equation that led to a nonlinear differential equation. References [8-11] all agreed that there is a need to develop an ecologically suitable strategy for harvesting any renewable resource. References [12-15] studied the optimal harvesting policies as their management intention over a random harvesting time perspective.

Constant harvesting is where fixed numbers of fish were removed each year, while periodic harvesting is usually thought of a sequence of periodic closure and openings of different fishing grounds $[16,12]$. In proportional harvesting, a constant fraction of fish is removed each year, thus, the quantity harvested is proportional to the population $[15,4]$. Harvesting has been considered a factor of stabilization, destabilization, improvement of mean population levels, induced fluctuations, and control of non-native predators [17]. Further reference on harvesting strategies can be found in [18-21].

Meanwhile, fish farming in Bade has a pronounced prospective in economic contribution and supplying fish for food consumption. It has been commercialized but there is little or no literature available in studying fish harvesting strategy in Bade. Thus, mathematical models do not widely feature in studying fish harvesting management strategy in Bade. Hence, the need to use mathematical model to estimate fish harvesting management strategies that will ensure the catch fish supply is relatively continuous and not get to extinction but fulfill the consumer demand.

The main aim of this work is to study three harvesting management techniques (constant harvesting, periodic (seasoning) harvesting and proportional harvesting model) of the fish population in fishing sites (lake or pond) in Bade (Gashua), Yobe State. The specific objectives are:

To develop a modified logistic growth model that includes harvesting rates,

To determine the maximum sustainable yield (MSY) of the fish population in a period,

To compare the results obtained between the three strategies. The strategies will ensure the supplies are continuous and the fish population stays is stable and make fish farming as a consistence source of income to Bade (Gashua) and an effective means of economic growth of the area.

\section{Method}

The data for this research has been obtained from the primary source from fish owners of the selected pond in Bade (Gashua), Yobe State. The selected pond has an area of $1.48 \mathrm{Ha}$, which is equivalent to $14800 \mathrm{~m}^{2}$, the sustainable or carrying capacity, $\mathrm{K}$ of the pond is 54000 fish. The period of maturity for the catfish is 6 months and estimates that $85 \%$ will survive to maturity. Also see [22]. We use qualitative analysis to estimate how many fish can be harvested and still allow the fish population to survive.

There are some mathematical models that were used to model the fish population that is undergoing harvesting [15, $16,19]$. The following describes some of the models.

The Gompertz growth model introduced by Benjamin Gompertz in 1825 is similar to the logistic growth model define as:

$$
\frac{d N}{d t}=r N I n\left(\frac{N}{K}\right) \quad N(0)=N_{0}
$$

The solution to this initial value problem can be solved as a first order separable differential equation and can be written as:

$$
N(t)=K\left(\frac{N_{0}}{K}\right) e^{-r t}
$$


Gompertz modified this model to as

$$
\frac{d N}{d t}=g(N(t))-h(N(t)), \quad N(0)=N_{0}
$$

The logistic growth model for our research is described by the differential equation $[6,16]$.

$$
\frac{d N}{d t}=r N\left(1-\frac{N}{K}\right)
$$

Three types of harvesting strategies were developed as follows:

The logistic growth model with constant harvesting;

$$
\frac{d N}{d t}=r N\left(1-\frac{N}{K}\right)-H(t)
$$

The logistic growth model with periodic harvesting;

$$
\frac{d N}{d t}=r N\left(1-\frac{N}{K}\right)-H(t)
$$

Where;

$$
\begin{gathered}
H(t)= \begin{cases}H_{0}, & 0 \leq t \leq 6 \\
0, & 6<t \leq 12\end{cases} \\
H(t+12)=H(t)
\end{gathered}
$$

The logistic growth model with proportional harvesting;

$$
\frac{d N}{d t}=r N\left(1-\frac{N}{K}\right)-H N, \quad N(0)=N_{0}
$$

The parameters for these models are:

$$
\begin{gathered}
N=\text { the population size } \\
N(t)=\text { the population size at time } \mathrm{t} \\
r=\text { the rate of fish survival at maturity stage } \\
K=\text { the carrying capacity of the population } \\
H=\text { harvesting function } \\
H(t)=\text { Periodic function of time per year } \\
t=\text { time in months } \\
x=\text { fishing site } \\
H_{0}=\text { harvesting function }
\end{gathered}
$$

\section{Results and Discussion}

The values of the parameters in the model are $r=0.85$, an estimation of the fish that will survive at the maturity stage and the pond carrying capacity $K=54000$. At the equilibrium point also known as a critical or stationary point, the fish population remains unchanged. From the Logistic Growth Model without fishing, the equilibrium points were obtained as shown:

$$
\begin{gathered}
\frac{d N}{d t}=0 \\
r N\left(1-\frac{N}{K}\right)=0
\end{gathered}
$$

Substituting the values of the parameters, we have

$$
0.85 N\left(1-\frac{N}{54000}\right)=0
$$

By the zero property theorem, we have

$$
\begin{aligned}
& 0.85 N=0 \\
& \Rightarrow N=0
\end{aligned}
$$

Also

$$
\begin{aligned}
& 1-\frac{N}{54000}=0 \\
& \frac{N}{54000}=1 \\
& \Rightarrow N=54000
\end{aligned}
$$

Thus, $N=0$ and $N=54000$. This means that if the initial population started with say $\mathrm{N}=0$, the population remains at that level $(\mathrm{N}=0)$. Equally, if the initial population started with say $\mathrm{N}=54000$, the population remains at the same. From the stability of this equilibrium point, as can be seen from Figure 1 were we obtained two values of an equilibrium points.

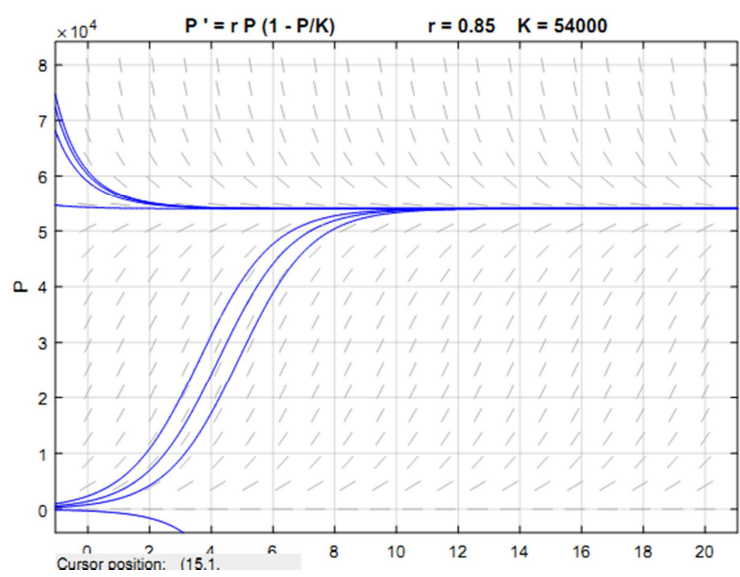

Figure 1. Constant Harvesting. $r=0.85, K=54000$.

Table 1 is used to illustrate the interval of the equilibrium points that shows whether the equilibrium point is stable or otherwise. We would see from the interval $(0,54000)$ that $\mathrm{N}=0$ is an unstable equilibrium point because solutions near this point are repelled or asymptotic. This means, given an initial population of fish $\mathrm{N}_{0}$, a little above $\mathrm{N}=0$ and the $N_{0}$ less than 0 , the population grows away from $\mathrm{N}=0$. The equilibrium point $\mathrm{N}_{0}=54000$ is a stable equilibrium point because solutions near this point are attracted to it. This means given an initial population in the interval $(0,54000)$, the population increases and reaches $\mathrm{N}=54000$, and remains at the same level. Likewise, if the population $N_{0}$, is greater than 54000, then the population declines and approaches a limiting value 54000 . 
Table 1. Interval of Equilibrium Point for the Logistic Growth Model

\begin{tabular}{llll}
\hline Interval & Sign of f (N) & N (t) & Arrow \\
\hline$(\infty, 0)$ & Plus & Decreasing & Point Down \\
$(0,54000)$ & Plus & Increasing & Point Up \\
$(54000, \infty)$ & Minus & Decreasing & Point Down \\
\hline
\end{tabular}

\subsection{Logistic Growth Model with Constant Harvesting}

The Logistic Growth Model with constant harvesting is as follows:

$$
\frac{d N}{d t}=r N\left(1-\frac{N}{K}\right)-H(t)
$$

where $r=0.85, K=564000$ and $\mathrm{H}$ is constant. To determine the equilibrium points for $\mathrm{H}$, we have

$$
\begin{gathered}
0.85 N\left(1-\frac{N}{54000}\right)-H=0 \\
0.85 N-\frac{0.85 N^{2}}{54000}-H=0 \\
0.85 N-0.0000157407 N^{2}-H=0
\end{gathered}
$$

By comparing with the general quadratic equation: $a x^{2}+b x+c=0$

$$
\begin{gathered}
a=0.000157407, b=-0.85, c=H \\
N_{1,2}=\frac{-\left(-0.85 \pm \sqrt{(-0.85)^{2}-4(0.0000157407) H}\right.}{2(0.0000157407)}
\end{gathered}
$$

For the maximum sustainable harvesting rate, we let the expression under the square root sign equal zero, as follows:

$$
\begin{gathered}
(-0.85)^{2}-4(0.0000157407) H=0 \\
0.7225-0.0000629628 H=0 \\
H=11,475.0297001 \approx 11,475
\end{gathered}
$$

The value $H=11,475$ is the maximum sustainable yield (MSY) or the total allowance catch that can be harvested from the stock or the biomas. The value $H=11,475$ is called the bifurcation point, and at this point we considered three values of harvesting:

$$
\begin{aligned}
& \text { 1. } H=11475 \\
& \text { 2. } H>11475 \\
& \text { 3. } H<11475
\end{aligned}
$$

For $\mathrm{H}=11475$, we have

$$
N=\frac{-\left(-0.85 \pm \sqrt{(-0.85)^{2}-4(0.0000157407) 11475}\right.}{2(0.0000157407)}
$$

$$
26,956.63289165 \approx 26,956
$$

For $H=11475, N=26,956$, we could see from Figure 2 we have one (1) equilibrium points. For $N_{0}$ larger than 26,957; the equilibrium will decrease and approach to 26,956. Likewise for $N_{0}$ less than 26,956; the equilibrium will lead to extinction.
Table 2 is used to illustrate the interval of the equilibrium points that shows whether the equilibrium point is stable or otherwise.

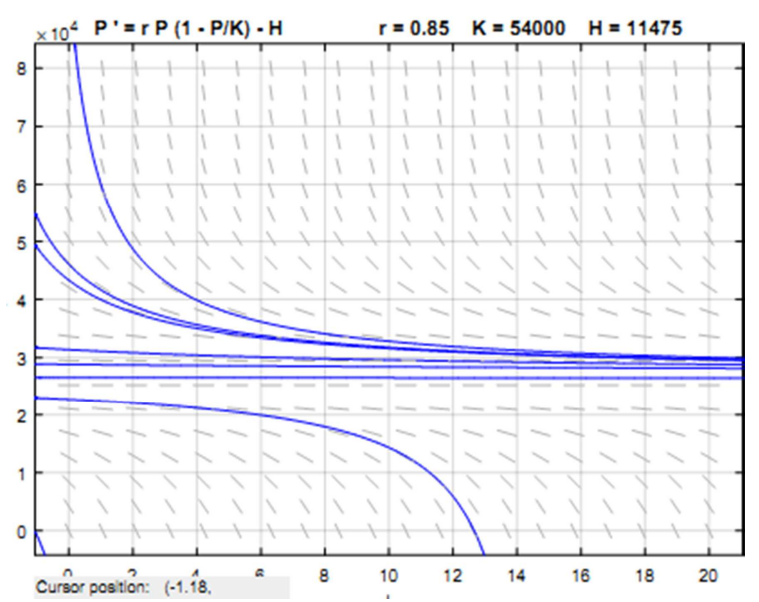

Figure 2. Harvesting, $H=11,475$.

Table 2. Interval of Equilibrium Point For Harvesting $H=11,475$.

\begin{tabular}{llll}
\hline Interval & Sign of $\mathbf{f}(\mathbf{N})$ & $\mathbf{N}(\mathbf{t})$ & Arrow \\
\hline$(-\infty, 26,956)$ & Plus & Decreasing & Point Down \\
$(26,956, \infty)$ & Minus & Decreasing & Point Down \\
\hline
\end{tabular}

For $H>11475$

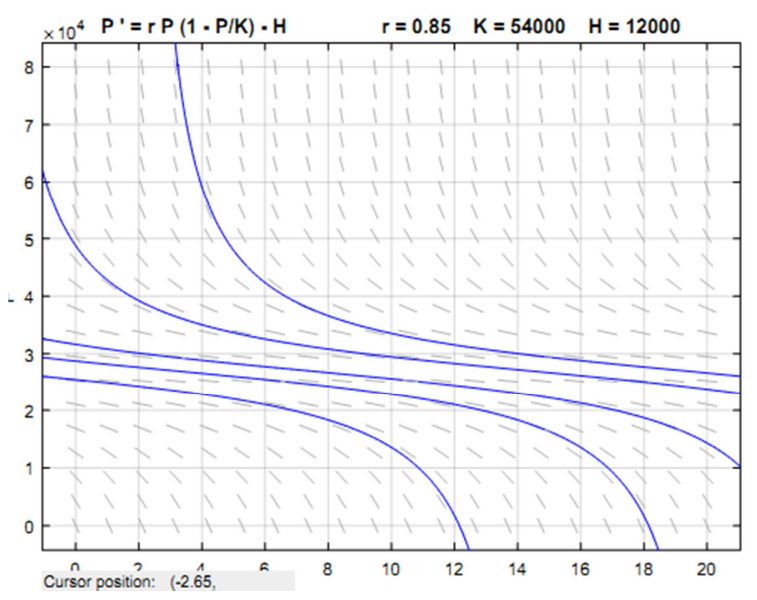

Figure 3. Harvesting $H=12,000$,

It could be seen from Figure 3 that the value of harvesting say $H=12,000$, shows the decreasing trends of catfish population. This indicates that the fish population will go to extinction notwithstanding of the initial population size. This is to say that overfishing during one year can possibly result in a sudden fall of the fish catch in succeeding years. Hence, the fish farmers need to be cautiously careful not to overcome 54000 in fishing quotas.

For $H>11475$

It could be seen from Figure 4 with the value of harvesting as $H=11000$, there will be two equilibrium points with an interval $(32,494, \infty)$ showing a decrease in the population of fish and the interval $(21506,32494)$ showing an increase in the fish population. The instability of the lower equilibrium point is due to the repelling solution near the point. 


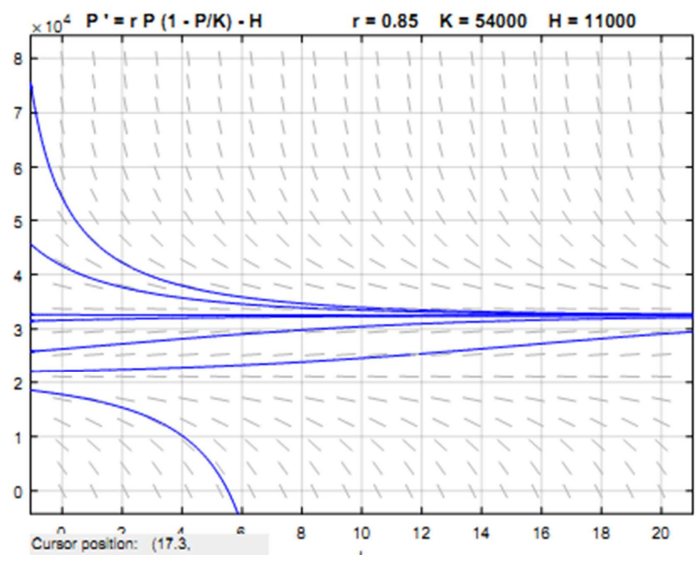

Figure 4. Harvesting $H=11,000$

Table 3 is used to illustrate the interval of the equilibrium points that shows whether the equilibrium point is stable or otherwise.

Table 3. Interval Of Equilibrium Point Harvesting $H=11,000$

\begin{tabular}{|c|c|c|c|}
\hline Interval & Sign of $f(N)$ & $N(t)$ & Arrow \\
\hline$(-\infty, 21506)$ & Minus & Decreasing & Point Down \\
\hline$(21506,32494)$ & Plus & Increasing & Point Up \\
\hline$(32494, \infty)$ & Minus & Decreasing & Point Down \\
\hline
\end{tabular}

Table 4 is the summary illustration of the results obtained from the constant harvesting strategies.

Table 4. Results from the Constant Harvesting Strategies.

\begin{tabular}{|c|c|c|}
\hline \multicolumn{3}{|c|}{ Constant Harvesting Strategies } \\
\hline$H=11,475$ & $H>11,475$ & $H<11,475$ \\
\hline $\begin{array}{l}\text { One equilibrium } \\
\text { point } \\
N_{0}=26,956\end{array}$ & $\begin{array}{l}\text { No equilibrium point } \\
\text { exist }\end{array}$ & $\begin{array}{l}\text { Two equilibrium point exist } \\
N_{0}=32494 \\
N_{0}=21596\end{array}$ \\
\hline $\begin{array}{l}\text { The equilibrium } \\
\text { point give the } \\
\text { initial population }\end{array}$ & $\begin{array}{l}\text { The considered initial } \\
\text { population values will } \\
\text { all lead to extinction }\end{array}$ & $\begin{array}{l}\text { The upper equilibrium point } \\
\text { is stable; else the lower } \\
\text { equilibrium point gives the } \\
\text { unstable population. }\end{array}$ \\
\hline
\end{tabular}

\subsection{Logistic Growth Model With Periodic Harvesting}

Another very used form of harvesting is when harvesting is done during a period of time within a year. The fish population will not be able to extinct during the fishing time since the harvesting rate is a periodic function and varies from season to season. If in some season the fishing is stopped, the population of fish might be able to increase again. The mathematical model can be written:

$$
\frac{d N}{d t}=r N\left(1-\frac{N}{K}\right)-H(1+\sin \omega t)
$$

Where the value of $r=0.85, K=54000, H=11475$ and $\omega=2 \pi$.

The pond has a full carrying capacity of 54000 catfish in the pond as an initial population. For the first 6 months, 11475 catfish are assumed for harvesting until the population of catfish remains 32494 and followed by no harvesting for the next six (6) months and continuous in this pattern repeatedly for several years. Staying out of harvesting in the next 6 months ensures the increasing population of the catfish. The population of the catfish increases until it approaches the carrying capacity $K=54000$.

We have two solutions that oscillate about the equilibrium point (Figure 5). Here, the solution converges to one periodic solution that oscillates around the stable fixed point. When $\mathrm{H}=11475$, we have only one fixed point (Figure 6). The fish population reaches the fixed point and stay there. When $\mathrm{H}$ increases more the fish population will extinct (Figure 7). Hence, this periodic equation has the same bifurcation point as model (8).

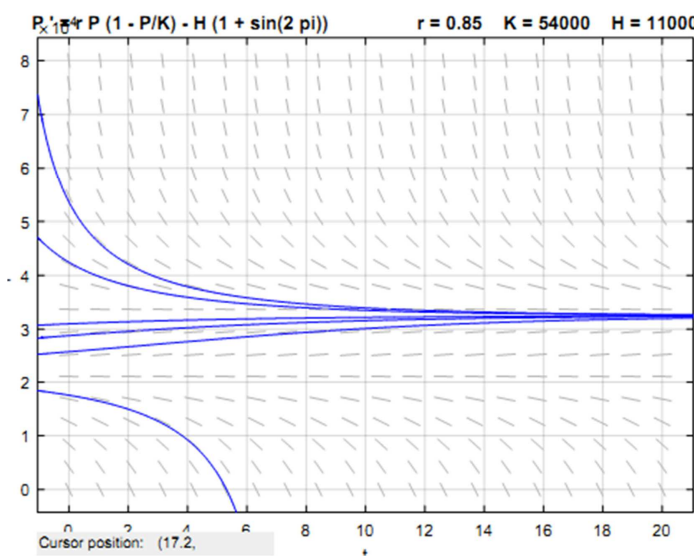

Figure 5. Harvesting $H=11,000$.

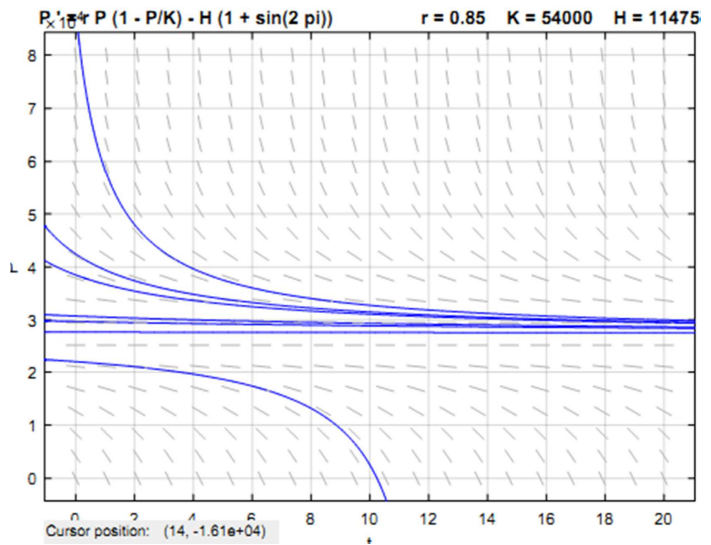

Figure 6. Harvesting $H=11,475$.

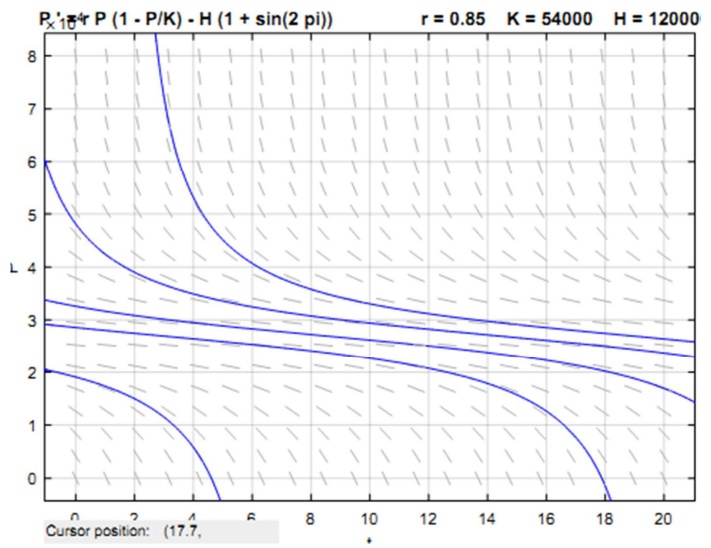

Figure 7. Harvesting $H=12,000$.

It is noticed that the periodic seasonal strategy optimizes the harvest while the fish population maintains a stable equilibrium. 
According to [2], a harvesting strategy using logistic periodic seasonal strategy can be used to improved productivity, shorten investment return time and reduce risk from changes in sale price and cost of production, particularly when comparatively short return period are used. In order frequent cases, we have some months, say, 3 months, where substantial fishing is allowed and other months where only low fishing is allowed. The population still recovers to equilibrium point but it generally takes longer duration to reach the stable fixed point. This is so because there are still a limited fish that are being harvested during the other part of the year.

\subsection{Logistic Growth Model With Proportional Harvesting}

Another common form of harvesting is when one puts in a constant effort to harvest. In this case, the quantity harvested is proportional to the population. Hence, the mathematical model can be written as:

$$
\frac{d N}{d t}=r N\left(1-\frac{N}{K}\right)-H N, \quad P(0)=P_{0}
$$

where again $r$ is the rate of fish survival, $K$ is the carrying capacity with no harvesting and now $H$ is the proportional rate of harvesting.

The Algebraic solution is complex and difficult to interpret; hence we again turn to the geometric analysis of the model. The equilibrium points of (8) are the solution of the equation: $r N^{*}\left(1-\frac{N^{*}}{K}\right)=H N^{*}$, that is $N^{*}=0$ and $N^{*}=\frac{(r-H) K}{r}$. The extinction equilibrium point $N^{*}=0$, is unstable for the value of $H<r$. As $\mathrm{H}$ increases, the larger equilibrium (carrying capacity, K) shrink, but it remains stable for $H<r$. For $H=0, N^{*}=K=54000$.

As the harvesting increases, the nontrivial equilibrium point will move closer to an extinction equilibrium point. As $\mathrm{H}$ moves toward the growth rate $(0.85)$, the nonzero equilibrium point will diminishes to zero, which indicates that there is extinction because the harvesting rate approaches the growth rate. When $H>r(=0.85)$, the rate of harvesting surpasses the reproduction rate and extinction automatically follows. This model illustrates a typical example of a transcritical bifurcation. The bifurcation point is $H=r(=0.85)$ (Figures $8,9,10)$.

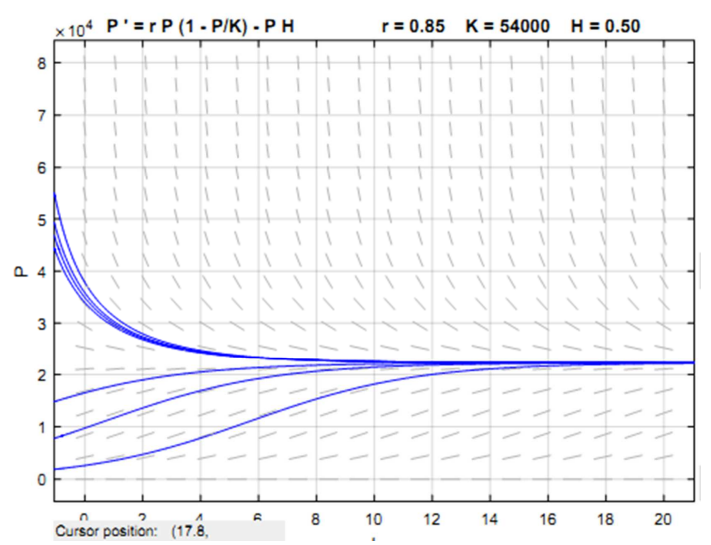

Figure 8. Harvesting $H=0.50$.

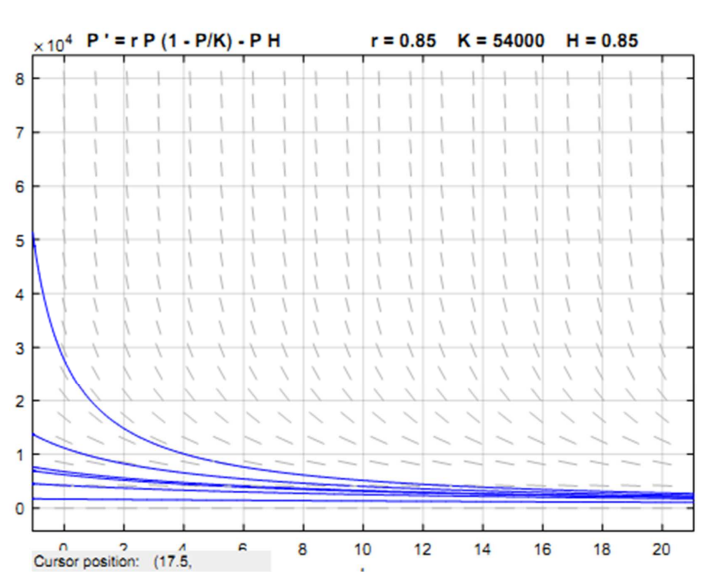

Figure 9. Harvesting $H=0.85$.

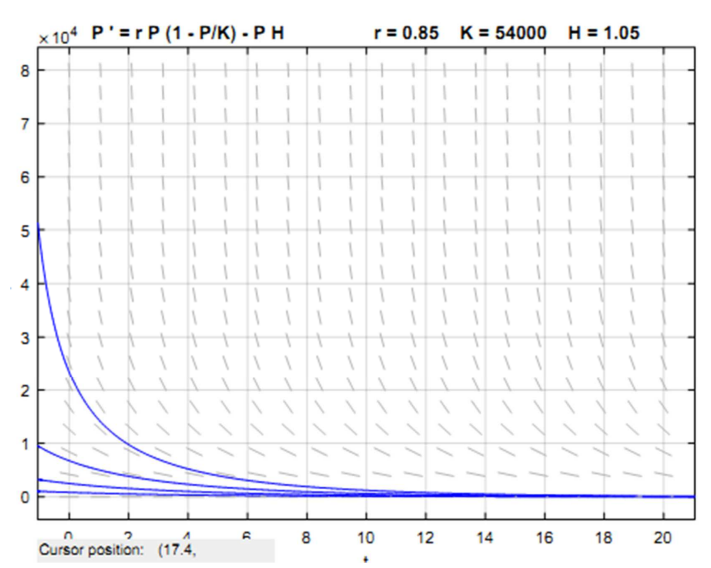

Figure 10. Harvesting $H=1.05$.

The results indicate that overfishing (in the model $H>r$ ), during one year can potentially extinct the fish in the lake or pond. Accordingly, the statutory bodies (government and other agencies) involved in the area need to be cautiously careful not to exceed the fishing quotas.

\section{Conclusion}

When dealing with practical applications that involve differential equations, it is very often that the differential equation contains parameters and the values of these parameters are often only known approximately. Hence, it becomes necessary to study the behavior of solutions and examine their dependence on the parameters. In most cases, a slight variation in a parameter can have a significant impact on the solution.

In this work, we have studied the sustainable harvesting strategies of the catfish population in a pond. We intended to explore harvesting strategies that optimize catch while still maintain a sustainable catfish fishing industry. We discussed three types of logistic growth models: logistic growth model with constant harvesting, logistic growth model with periodic harvesting, and logistic growth model with proportional harvesting. For successful management of harvesting, the population is very important that harvesting strategies are sustainable, not leading to instabilities or extinctions and 
produces great results for the year with little variation between the years.

From our discussion of the three harvesting strategies, the implementation of the logistic constant harvesting strategy of the selected fish pond with carrying capacity of $54000 \mathrm{~m}^{2}$, the maximum sustainable yield (MSY) or the total allowable catch that can be harvested from the population is 11475 tons of fish. If the MSY is constantly removed from the population, the fish population does not have time to recover the fish population; as such the fish population gets to extinction.

However, for the logistic periodic (seasonal) harvesting strategy, 11475 tones catfish is assumed for harvesting for the first six (6) months until the population of catfish remains 32494. This is followed by no harvesting for the next 6 months in order to allow the fish to repopulate until it approaches the carrying capacity of $54000 \mathrm{~m}^{2}$. This pattern is being repeated for several years. Hence, the periodic harvesting strategy optimizes the harvest while maintaining stable the population of fish if the harvesting is lower or equal with the bifurcation point. The logistic periodic (seasonal) harvesting strategy can be used to improve productivity, shorten investment return time and reduce risk from changes in the sale price of fish and costs of productions of fish, particularly when comparatively short return periods are used.

Concerning the proportional harvesting strategy, the fish populations will extinct if the proportional rate of harvesting is greater than the growth rate of the population or the bifurcation point.

The development of appropriate fishery harvesting strategy perhaps can supply the market demand throughout the year. It can also improve the commercial return to farmers before harvesting while successful management of harvested population helps the fishery industry to grow both qualitatively and quantitatively. The supply of fish cannot rely only on the ocean/seas fishing activities. Commercializing the aquaculture could be a good alternative.

\section{Recommendation}

Based on the results of the study, we, therefore recommend the following:

A periodic harvesting strategy for fish farmers, since it is a more stainable technique in fishery management practices.

The Government, particularly the Ministry of Agriculture and Rural Development, is encouraged to use this study as part of its guidance for training prospective fisher farmers.

Workshops and seminars should be regularly organized to educate fish harvesters and other stakeholders on a more sustainable harvesting strategy and be well monitored to ensure its usage.

Entrepreneurs in Bade (Gashua) town and Yobe State, in general, will know the effect of constant harvesting and thus should be able to choose the one that is more beneficial.

Artisanal should form themselves into cooperatives to be able to access credits and other inputs in order to enter into the fishery industry.

Finally, we recommend for further study, the extension of our models to include issuing of Fishing Licenses and the oxygen content of the body of water in the pond.

\section{Conflict of Interest}

The authors declare no conflicts of interest regarding the publication of this paper.

\section{Acknowledgements}

The authors would like to acknowledge the Management of Federal University Gashua for providing funding via the Tertiary Education Trust Fund (TETFund).

\section{References}

[1] R. Asmah, "Development potential and financial viability of fish farming in Ghana (Doctoral dissertation)," University of Stirling, Stirling, UK, 2008 [Online]. Available: http://citeseerx.ist.psu.edu/viewdoc/download?doi=10.1.1.845 $.2582 \&$ rep $=$ rep $1 \&$ type $=$ pdf.

[2] M. F. Laham, I. S. Krishnarajah, and J. M. Shariff, "Fish Harvesting Management Strategies Using Logistic Growth Model,”Sains Malaysians, vol. 41 (2), pp. 171-177, 2012.

[3] FAO, (2009). A Fishery Manager's Guide Book, $2^{\text {nd }}$ Ed. Editors: K. L. Cochrane and S. E. M. Garcia, John Wily \& Sons, United Kindon, [Online], Available: http://www.fao.org/3/i0053e/i0053e.pdf.

[4] V. Shehu and A. B. Spaho, "BIFURCATION ANALYSIS AS A USEFUL TOOL TO FISHERY MANAGEMENT," Journal of Natural and Technical Sciences, Vol. 20 (2), pp. 17-26, 2015.

[5] S. B. Adams, "Direct and Indirect Effects of channel catfish (Ictalurus punctatus) on Native Crayfishes (Cambaridae) in Experimental Tanks," The American Midland Naturalist, 158 (1), pp. 58-95, 2007 [Online]. Avialable: https://naldc.nal.usda.gov/download/13465/PDF.

[6] D. J. Murray, "Mathematical Biology: I. An Introduction," $3^{\text {rd }}$ Ed, Springer, New York, 2001.

[7] A. A. Berryman, "The Origins and Evolution of Predator-Prey Theory." The Ecological Society of America, vol. 73, no. 5, pp. 1530-1535, $1992 . \quad$ [Online]. Avialable: http://homepages.wmich.edu/ malcolm/BIOS6150-Ecology/D iscussion\%20References/Berryman-Ecology1992.pdf.

[8] B. Dubey, P. Chandra and P. Sinha, "A Model for fishery resource with reserve area, Nonlinear Analysis: Real World Application, vol. 4, pp. 625-637, 2003. [Online]. Available: http://home.iitk.ac.in/ peeyush/pdf/nla_bd_pc_ps.pdf.

[9] J. Ward, P. M. Mace and E. Thunberg, "The Relationship of Fish Harvesting Capacity to Excess Capacity and Overcapacity," Marine Resource Economics, vol. 19, pp. 525-529, 2004.

[10] B. Mondal, A. K. Bhunia and M Maiti, "Optimal two-species harvesting policy with price and Size (biomass) of the fish population dependent catch rate function," Applied Mathematics and Computation, vol. 187, pp. 600-608, 2007. 
[11] T. Prince, "A NEW MODEL OF HARVESTING FISH POPULATION," International Journal of Applied Mathematics, vol. 30, no. 4. Pp. 345-350, 2017. [Online]. Available:

http://www.diogenes.bg/ijam/contents/2017-30-4/6/6.pdf.

[12] M. Fan and K. Wang, "Optimal harvesting policy for single population with periodic coefficients," International Journal of Mathematical Biosciences, vol. 152, pp. 167-177, 1998.

[13] W. Jing and W. Ke, "Optimal control of harvesting for single population." Applied Mathematics and Computation 156, pp. 235-247. 2004a. [Online]. Available: http://www.paper.edu.cn/scholar/showpdf/NUD2cN1IMTT0Q $\mathrm{xeQh}$.

[14] W. Jing and W. Ke,“ The optimal harvesting problems of a stage-structured population." Applied Mathematics and Computation vol. 148, pp. 235-247., 2004b. [Online]. Available:

http://www.paper.edu.cn/scholar/showpdf/NUD2cN1IMTT0M xeQh.

[15] W. Li and K. Wang, "Optimal harvesting policy for general stochastic logistic population model," Journal of Mathematical Analysis and Applications 368, pp. 420-428, 2010.

[16] L. V. Idels and M. Wang, "Harvesting fisheries management strategies with modified effort function," International Journal Modelling, Identification and Control, vol. 3 no. 1, pp. 83-87, 2008.

[17] I. D. S. C. Michel, "Harvesting induced fluctuations: insights from a threshold management policy," Mathematical Biosciences, vol. 205, pp. 77-82, 2007.
[18] Cooke, K. L. and Nusse, H. (1987). Analysis of the complicated dynamics of some harvesting models. Journal of Mathematical Biology, Vol. 25, pp 521-542.

[19] D. Ludwig, "A theory of sustainable harvesting," SIAM Journal of Applied Mathematics, 55 (2), pp. 564-575, 1995.

[20] A. Daci and A. Spaho, "BIFURCATION IN A DYNAMICAL SYSTEM: HARVEST MODELS." The 1st International Conference on Research and Education-Challenges Toward the Future (ICRAE2013), 24-25 May 2013, University of Shkodra "Luigj Gurakuqi", Shkodra, Albania. [Online]. Available:

http://konferenca.unishk.edu.al/icrae2013/icraecd2013/doc/41 1.pdf.

[21] A. Daci, "Fish Harvesting Models And Their Applications in a reservoir in Saranda, Albania," Journal of Multidisciplinary Engineering Science and Technology (JMEST) ISSN, vol. 3, pp. 2458-9403, 2016. [Online]. Available: http://www.jmest.org/wp-content/uploads/JMESTN42351707. pdf.

[22] A. A. Okeke, P. R. Waziri-Ugwu, A. D. Abubakar, J. J. Gambo, "Mathematical Modelling as a Sustainable Technique for Fishery Management and Economic Growth in Gashua, Yobe State, Nigeria," IOSR Journal of Mathematics (IOSR-JM), e-ISSN: 2278-5728, p-ISSN: 2319-765X. Vol. 16, Issue 2 Ser. I PP 11-22, $2020 . \quad$ Online: http://www.iosrjournals.org/iosr-jm/papers/Vol16-issue2/Serie s-1/C1602011122.pdf. 